This is an Accepted Manuscript of an article published by Taylor \& Francis Group in Journal of Marketing Communication on 22 Apr 2015, available online:

http://www.tandfonline.com/10.1080/13527266.2015.1015108.

\title{
Appealing to men and women using sexual appeals in advertising: In the battle of the
}

sexes, is a truce possible?

Iain R. Black ${ }^{\mathrm{a} 1}$ and Peta Morton ${ }^{\mathrm{b}}$

${ }^{\text {a }}$ School of Management and Languages, Heriot Watt University, Edinburgh, Scotland

${ }^{\mathrm{b}}$ Banjo Advertising, Sydney, Australia

Sexual appeals remain a very popular advertising technique yet questions regarding their use remain, including how they can be used to appeal to men and women simultaneously. Literature examining what men and women find sexually appealing and the body language used to signal relationship status guided development of two appeal types: 'Intimate' portrayed a couple in an intimate stable relationship whereas 'Objectified' showed them as sexual objects. These were combined with different levels of nudity and product relevance and studied experimentally. As expected, both genders preferred intimate appeals though they only rated low nudity intimate adverts for relevant products positively.

Keywords: advertising; sexual appeals; body language; experiment

\footnotetext{
${ }^{1}$ Corresponding author: I.R.Black@hw.ac.uk
} 
Sex and sexual appeals remain an important and widely utilized platform for promoting a broad range of products and services. Indeed, Reichert, Latour and Ford (2011) suggest its use is now the norm for advertising products such as cosmetics and perfume. Whereas significant amounts of research questions how and if 'sex sells' (see for example Dahl, Sengupta and Vohs 2009 or Giebelhausen and Novak, 2012), particularly for female audiences, recent research has helped develop a nuanced understanding of the relationship between gender and response to sexual appeals. This work has shown, for example, that cueing relationships or targeting those with certain personality types or a propensity to seek sensations, can lead some women to respond positively to sexual appeals (Dahl, Sengupta, and Vohs 2009; Reichert, LaTour, and Ford 2011; Black, Morton, and Organ 2010).

Whilst this work shows that women's responses can be positive or improved, overall, research supports the view that irrespective of what is done in terms of the models and levels of nudity used, the types of product advertised or sex role portrayals; men and women typically respond differently to sexual appeals. Indeed most often, women will respond less favourably (Sengupta and Dahl 2008; LaTour and Henthorne 1993; Orth and Holancova 2004; Simpson, Horton, and Brown 1996; Smith et al. 1995).

However, this difference is an important issue for advertisers and marketing managers as there are several situations where they must consider the responses of both men and women simultaneously and where a sexual appeal may be a legitimate, effective, creative form. These situations include products targeted at one group but whose purchase or use is influenced by the other (chocolate, perfume, clothing, lingerie, underwear) and products targeted and consumed by both sexes (wine, carbonated soft drinks, beds). In addition, media targeting is not perfect (Johnson 2013; Crosier et al. 1999) and managers need to understand the consequences of using sexual appeals on both men and women simultaneously. 
Considering the differing responses, should organisations avoid using this type of appeal when targeting men and women at the same time? Currently, there is a lack of research to help answer this question and help managers understand the potential benefits and limitations this approach has in terms of advertising effectiveness and branding.

The research reported here aims therefore to examine how to appeal to men and women simultaneously when using sexual appeals and makes both practical and conceptual contributions. It takes a heterosexual perspective and leaves the gay, lesbian and bisexual perspectives for later study. From a practical perspective it adds to work on executional elements in advertising (Fennis, Das, and Fransen 2012; Rossiter 2012). It provides specific instructions on how to pose models in terms of their body position, type of eye contact and physical touching (and what characteristics they should display), when designing sexual appeals to be enjoyed by both men and women.

Conceptually, it highlights how, contrary to much of the work in the area (Dahl, Sengupta, and Vohs 2009; Putrevu 2004; Smith et al. 1995) female subjects can enjoy sexual advertising appeals if they are constructed using consensual, intimate displays of affection between the models. It also helps explain the negative reactions by women and men toward adverts using higher levels of nudity (LaTour and Henthorne 1993) and men's negative responses when male models are used (Reichert et al. 2007) .

\section{Theoretical background and hypotheses}

\section{Appealing to men and women: An impasse?}

Research over a significant period of time shows that men tend to respond more favourably to sexual appeals than women (Dahl, Sengupta, and Vohs 2009; LaTour and Henthorne 1993, 1994; Putrevu 2008; Sciglimpaglia, Belch, and Cain 1978; Sengupta and Dahl 2008; Smith et al. 1995). This appears to hold over a number of conditions such as level of nudity (LaTour 
and Henthorne, 1993; Simpson, Horton, and Brown 1996), the gratuitous use of sexual appeals (Sengupta and Dahl 2008), relevance or 'fit' between the product and the use of sexual appeals (Peterson and Kerin 1977) and the use of a number of different dependent measures including attitude toward the advertisement, attitude toward the brand and purchase intention (LaTour and Henthorne 1993; Putrevu 2004).

The lesson seems to be that as long as there are attractive women used within the advertisements, then men, on the whole will respond positively. This is not to say that men like sexual appeals and women don't (Reichert, LaTour, and Ford 2011) nor that they like all types of appeals the same, but instead, that they are less discriminating and less likely to be 'turned off' by for example by gratuitous use or overt visual displays. For women, it seems a more subtle and nuanced approach is required, (Dahl, Sengupta, and Vohs 2009; Pope, Voges, and Brown 2004; Sengupta and Dahl 2008) with women tending to prefer verbal and complex messages (Putrevu 2008) compared to the preference for visual stimuli by men.

If we are going to use sexual appeals to target both men and women, where does this leave us? Considering the above and that overall research supports the notion that women are less stimulated by visual media (Rupp and Wallen 2008), we argue that when constructing advertisements for a mixed sex audience, they should be based on the type of stimulus and features that women have been found, overall, to find sexually attractive. Whilst this may not necessarily be the best way to communicate to men, it is likely, because of its sexual nature, to appeal to them nonetheless. This then leads to the question of how best to achieve this? The next section, considers evidence regarding responses to sexual appeals and what the different sexes find attractive, to develop appeals to which men and women may respond favourably. 


\section{Product relevance}

Product relevance refers to whether the product being promoted has pre-existing sexual connotations and hence whether it is 'relevant' to use sexual appeals (Peterson and Kerin 1977). It has been found to have a significant effect on men and women's ratings of these types of appeals where advertisements for relevant products are rated more highly (appealingPeterson and Kerin (1977) or liking- Sengupata and Dahl (2008) compared to those for products without such meanings. Hence, due to the importance of this factor and that the literature reviewed does not suggest the relationship will be modified by the type of appeals to be tested and that we do not plan to constrain processing (Sengupta and Dahl 2008) relevance is integrated into the type of appeal hypotheses. It is expected that irrespective of gender, adverts for relevant products will be preferred to those for irrelevant products.

\section{Women's preferences}

Whereas the sexual appeals literature has given considerable attention to the importance that men attach to physical attractiveness (for example see Putrevu 2008), it is clear that women also rate this as important, though what differs are the traits for which they are looking (Buss and Barnes 1986).

Li, Bailey, Kenrick, and Linsenmeier (2002) found that both men and women assess potential mates for sufficient levels of physical attractiveness and status though what differed was the standard they had to reach. So what do women tend to find attractive in men? They tend to prefer a high waist-to-chest ratio (Maisey et al. 1999), higher levels of muscularity, lower levels of fat (Weeden and Sabini 2005) and above average height (Pawlowski, Dunbar, and Lipowicz 2000). As with men, however, physical attractiveness is assessed holistically and its characteristics such as waist to hip ratio (WHR), body mass index, hormone markers, 
averageness, symmetry and skin texture, are considered together (Grammer et al. 2003).

These attractiveness cues are linked to health and reproductive fitness (Buss and Barnes 1986).

Beyond physical attractiveness, women may also find signs of wealth and status attractive (Kenrick et al. 2001) and Symons (1979) showed that women are positively aroused by acts of intimacy. This view is supported by Leitenberg and Henning (1995) who found that women use more romantic imagery when fantasizing about sex. Hill (2002) takes this further and showed women were more likely to engage in sexual activity if it is described in an emotionally committed, intimate situation. In work specifically on advertising, Dahl et al. (2009) discussed how 'relationship commitment' is a valuable resource that men can provide for women in a sexual situation and showed that when male models provided a gift in the picture (signifying a commitment to the relationship), then women's ratings of sexual advertisements improved. Taken together this work suggests women react more favorably toward sexual stimuli that include cues of intimacy and relationship commitment.

A common observation of sexual appeals in advertising is that they portray a heterosexual male view of what is attractive (Reichert and Carpenter 2004; Stankiewicz and Rosselli 2008) and hence the findings that women are less aroused by this comes as no surprise. Hence it is a rather unsurprising nuance in this debate that women do react positively to sexual visual stimuli if they are tailored to them (Dahl, Sengupta, and Vohs 2009; Simpson, Horton, and Brown 1996). For example, Youn (2006) argues that women's generally lower arousal by pornographic films compared to men (Mosher and Maclan 1994), is due to the male orientation typically used. Indeed, Laan et al. (1994) and Mosher and Maclan (1994) find that women are aroused if the visual erotica is based on equal enjoyment of non-denigrating, consensual activities between actors portraying a pre-existing relationship. This suggests that not only should women prefer sexual stimuli using models posed to display an intimate, committed relationship, but in doing so, beyond just improving women's ratings they may 
actually enjoy this type of stimulus. Therefore the physical, resource and relationship characteristics described above provide the framework used for constructing one type of sexual appeals labelled Intimate to be tested in this study. For this type, a mixed sex couple of physically attractive models are posed to demonstrate intimate, stable relationships and the propensity to remain loyal (Dahl, Sengupta, and Vohs 2009; Leitenberg and Henning 1995; Symons 1979). Details of the specific posing used are provided in the Stimuli section.

As this research examines advertisements featuring both a man and a woman, we must consider the female viewer's reaction to the female model. Social comparison theory describes how women typically compare themselves to models on the basis of physical attractiveness (Striegel-Moore, McAvay, and Rodin 1986) with numerous authors finding that this can have a negative effect on women's self-esteem and body satisfaction (See for example Martin and Gentry 1997; Mills et al. 2002).

However, women can react positively to models if they present a beauty ideal that is seen as achievable (i.e. not too thin nor their bodies too attractive) and activates a selfimprovement goal (Bower and Landreth 2001). Therefore, if a female model used in an advertisement is not highly attractive and does not openly display her beauty or physical resources in an 'objectifying' manner, then she is not expected to pose a specific threat to the female respondents or invoke damaging negative self-comparison.

If, however, the female model makes conspicuous displays of her body, and the female respondents feel threatened, then they are likely to respond using indirect aggression (Griskevicius et al. 2009). Common forms of this include spreading gossip and making derogatory comments which in turn negatively influence how the model and advert are assessed (Bower and Landreth 2001; Griskevicius et al. 2009).

To provide a comparison to the Intimate appeals, these demonstrations of physical attributes are used to help develop an Objectified type appeal where models are posed to 
display themselves and their partners as sexual objects and show their sexual availability to others. Indeed, examples of these types can be found in print advertising and according to Reichert et al. (2011) are increasingly prevalent, thus, making a test of their effectiveness relevant to practice.

H1 (a): Women will prefer advertisements where the models are posed in an intimate manner compared to those where they are posed in an objectifying manner. In addition, they will evaluate intimate appeals featuring relevant products positively.

\section{Men's preferences}

We also expect that men will respond positively to sexual appeals that contain a physically attractive female model. However, men also tend to be attracted to evidence that potential partners have the mental resources to form close, intimate relationships and be faithful and loyal (Li and Kenrick 2006; Buss and Dedden 1990). Indeed, men are able to detect (Burriss and Little 2006) and react to signs of infidelity (Buss and Shackelford 1997). Hence, they are likely to find appeals, where an attractive female model is posed in a way to show she is capable of a stable relationship, more attractive compared to appeals showing an attractive female model showing signs that she may be unfaithful. As described earlier, cues to these traits are incorporated into the Intimate and Objectified appeals.

Regarding the likely reaction to the male model, Hill (2007) showed that men overestimate how attractive rivals are to women, and hence see potential competition as more of a threat than they should. In turn, this can lead to aiming derogatory statements toward the competitor, direct aggression or more likely here, avoiding the competition by looking away and avoiding the advertisement (Griskevicius et al. 2009). Social comparison theory also supports the notion that viewing a rival who possesses superior resources can have negative effects on men and whilst their self-image appears to be more robust, it can still be damaged (Jones 2001; Morry and Staska 2001). Therefore, if the male model is posed so that he does 
not make a conspicuous display of his body shape ('V') nor financial or other status related resources, and hence appears as less of a threat, then male respondents should not have a strong negative reaction to him. If on the other hand the male model makes a conspicuous display of his physical resources (as is planned for the 'objectified' condition) then a negative reaction can be expected. Therefore, we hypothesize that:

H1 (b): Men will also prefer intimate appeals to objectified appeals, but they will evaluate positively both intimate and objectifying appeals featuring relevant products.

Advertising research conducted over a number of years and exploring the impact of a number of different stimulus and individual difference variables, has consistently found that, overall, men respond more favourably than women to sexual appeals containing couples (for example see Dahl, Sengupta, and Vohs 2009; or Putrevu 2008). Therefore, despite focusing on creating stimuli designed to appeal to women, we hypothesize that:

H1 (c): Men, will respond more favorably to sexual appeal than women irrespective of whether the mixed gender couple are posed in an Intimate or Objectifying manner.

\section{Gender and level of nudity}

When opposite sex models appear in advertisements (males viewing adverts with female models and vice versa), men typically prefer higher levels of nudity and women typically prefer lower levels (LaTour and Henthorne 1993; Simpson, Horton, and Brown 1996). The relationship differs though when mixed gender couples (male and female models posed together) are used. Here, men still responded more favorably via attitude toward the advertisement $\left(A_{\mathrm{ad}}\right)$ and attitude toward the brand $\left(A_{\mathrm{br}}\right)$ than women (Belch et al. 1982; Simpson, Horton, and Brown 1996), but both genders tend to prefer fully clothed to partially clothed or nude stimuli. 
Women's preference for lower levels of nudity is explained by their overall preference for cues of intimacy, status and resources (see for example Kenrick 2001) therefore increasing levels of male nudity are effectively giving them more of the wrong thing. For men, whilst they enjoy higher levels of female nudity; they do not enjoy seeing more of the male model (Reichert et al. 2007) and as described before, if he is assessed as being superior, then their self-image can be damaged and greater body image dissatisfaction (Morry and Staska 2001) can occur. Hence greater levels of male nudity are expected to reduce men's ratings of the adverts and we hypothesize that:

H2: Irrespective of whether the mixed gender couple are posed in an Intimate or Objectifying manner, both male and female subjects will respond more favorably to advertisements using lower levels of nudity compared to higher levels of nudity.

\section{Method}

A mixed factor experimental design was used where gender, type of sexual appeal (Intimate or Objectified) and level of nudity (High or Low) were the between-subjects factors. Relevance of the product to the appeal was the within-subjects factor and was also manipulated over 2 levels (Relevant or Irrelevant). Subjects were randomly assigned to one of four conditions, Low Nudity Intimate, High Nudity Intimate, Low Nudity Objectified and High Nudity Objectified.

\section{Stimuli material}

The stimulus material consisted of colour, print style ads featuring a mixed gender couple. To guide the development of how specifically to pose the models in order to demonstrate the required intimacy or objectification, work regarding relationship status and body language was reviewed. Nonverbal behaviour is used to demonstrate relationship status (i.e. being in a 
relationship or interested in forming one) with the actual behaviours used based largely on gender, the stage of the relationship and the actor's intentions (Moore 1985; Renninger, Wade, and Grammer 2004). In her widely cited article, Moore (1985) codes, in great detail, nonverbal behaviours used at the early stages of a relationship including behaviours used by women to start courtship by soliciting interest in men and behaviours used to demonstrate a bond has been formed. These works are therefore also used to operationalise the Intimate and Objectified types of appeal (Table 1).

\section{Intimate appeals}

These appeals used specific nonverbal behaviour elements that cue intimate affection commonly seen between couples in a stable relationship. A key element of this is synchronicity or posture mirroring: People demonstrate rapport and approval with each other by mirroring poses held by the other party and by mirroring sequences of behaviour until full body symmetry (where each part of the body mirrors their partner's) is attained (Grammer, Kruck, and Magnusson 1998). Within the Intimate appeals therefore, couples mirror, to a large extent, each other's body positions and do so using a closed stance as this restricts the display of strength or physical attractiveness to other parties and instead showing a bond between the couple (Renninger, Wade, and Grammer 2004).

Moore (1985) describes behaviour 'constellations' where several behaviours appear together to communicate the desired signal. A constellation was used for the model's faces to show affection and intimacy by having them gaze into each other's eyes and holding this eye contact (Moore 1985; Perper and Weis 1987). As it was important to show nurturing and close intimate contact (rather than sexually explicit contact) instead of kissing, the models heads touched (whilst keeping their noses a few centimetres apart) and they smiled at each other (Moore 1985). Physical contact with other parts of the body was used as it is a common 
sign that a relationship has progressed from the early 'attention getting' stages. To operationalise this, the models caressed the head of their partner (Moore 1985).

\section{Objectified appeals}

In contrast, the Objectified appeals were presented through nonverbal behaviours that are gender specific cues for sexual interest. Key to this is for the women to express enough interest to elicit courtship by the man, whereas the man must display enough physical attractiveness and status (Blythe, Miller, and Todd 1996) to elicit a reaction. As the signals attuned to by each gender are different, the following instructions were given to the male and female model. When trying to solicit interest, how the female looks around the environment is very important. Moore (1985) describes how the women can instigate this phase by visually sweeping the location and briefly holding the gaze of perspective partners, this is quickly followed by looking away. Therefore, if the female model looks toward the camera she will simulate both the type 1 'room encompassing glance' and the type 2 'short darting glance' (Moore 1985, 239). To show interest, a further facial constellation was used encompassing a coy smile (partial opening of the lips and lowering the eyelids) and to show openness, her neck was elongating and presented (Grammer 1990; Moore 1985). The final key element for the female is to show her physical shape by standing in such a way as to split her hip (Braun and Bryan 2006) so highlighting a low WHR, a trait across cultures men tend to find attractive (Buss 1989).

For a man to sexually objectify himself and the person he is posing with, it is important for him to show his strength and status. A key way of doing this is to take up an open body position and open legged stance (Moore 1985; Renninger, Wade, and Grammer 2004). Finally, to show his intentions, rather than engage with the other model or with the 
audience he stares at her erogenous zones (Huber and Herold 2006). Figure 1 presents both the Intimate and Objectified appeals used.

Figure 1. Stimulus materials used

Table 1. Summary of specific elements used in the intimate and objectified conditions

\section{Level of nudity and product relevance}

The level of nudity (low and high) was operationalised through amount of clothing worn by models. Although full frontal nudity has been employed in previous research (see for example LaTour and Henthorne 1993), it is rarely used in advertising and avoided here. Instead, following the general approach used elsewhere (Huang 2004; LaTour and Henthorne 1993), in the low nudity condition models wore a white t-shirt and blue denim jeans and in the high nudity condition, they wore black underwear only. It is worth noting though that in following the approach provided by these authors we are using a North American culturally bound perception of high vs. low nudity and the results must be interpreted accordingly.

Half the treatment advertisements featured a product classified via pre-testing (as detailed during the procedure section) as sexually relevant (perfume and massage oil) and half featured products classified as irrelevant (muesli and USB Sticks). These were chosen to be applicable to both men and women, hence making the use of a mixed gender couple realistic. Fictitious brand names from Peterson and Ross (1972) were used -Vade' and 'Cariss' for relevant products and 'Dallacks' and 'Vig' for the sexual irrelevant products. 


\section{Production}

Colour photographs for the stimuli were taken by a professional photographer in a studio enabling lighting and background to be held constant. Professional models were selected, with the aid of their model agency manager, to have a 'neutral /classic' look as assessed using a set of standard cues to attractiveness such as low WHR for the female model, high WCR for the male model and clear skin tone (Grammer et al. 2003). Finally, experienced models were used to ensure that the posing would appear natural and the relationship genuine. Indeed, the photos used came from the second shoot as the two original models did not work well together and their posing appeared awkward and contrived. Two advertisements were created for each condition by a qualified graphics designer using a single design template to keep font size, style and background constant.

\section{Pre-test}

The adverts were pre-tested on 20 undergraduate students with the same profile as the main sample. Level of sexual appeal was measured with the single item scale anchored 'Mild sexual appeal' to 'Overt sexual appeal.' Intimacy ('Intimate' - 'Not Intimate') and Objectification ('Objectifying' - 'Not Objectifying') were measured using one item each as was Product Relevance ('Relevant' and 'Irrelevant'). All items were measured using seven point semantic differential response format. Model attractiveness was measured using Feick and Higie's three item scale (1992) using a 7 point likert scale anchored 'Strongly Disagree' to 'Strongly Agree.' The results (see Table 2) support the idea that the manipulations worked as expected. Importantly, the Intimate and Objectified appeals did not differ in how overtly sexual they were. Therefore, variations in responses to between these items cannot be attributed to how overt the appeals are. 
Table 2. Pre-test results

\section{Main data collection procedure}

Data were then collected from 128 (74 female, 54 male) undergraduate marketing students attending an Australian University and who completed the task for class credit. Their age ranged from 18 to 27 years (mean 20.3), which helped control for likely age effects (Elliott et al. 1995). As well as being appropriate for theory testing (Calder and Tybout 1999), this group provided an appropriate sample to enhance external validity as sexual appeal are commonly used to target students and young adults of this age.

Subjects attended a computer lab and were told the study objective was to 'discover how people respond to different advertising appeals.' Having been randomly assigned to one of the four treatment conditions, after reading the instructions and completing a practice example, subjects were exposed to 12 ads in randomised order. This number comprised the four targets (two stimulus replicates for the two levels of the relevance factor) and eight dummy advertisements (equal numbers of fear and humour appeals used to disguise the true nature of the research) each appeared on the screen for exactly five seconds. The dummy ads were also constructed for the purpose of the study and adhered to a similar format as the target ads. The dependent measures were then asked after each stimulus had been shown. Having viewed all 12 advertisements, demographic data was collected and the subjects de-briefed.

\section{Measures}

The dependent variables used were $\mathrm{A}_{a d}$ and $\mathrm{A}_{\mathrm{br}}$. Attitude toward the advertisement was chosen as it is a widely accepted measure of advertising effectiveness (LaTour and Henthorne 1994; Pope, Voges, and Brown 2004) and has been shown to mediate the relationship between advertising, brand attitudes and purchase intention (MacKenzie and Lutz 1989). It was 
measured using seven items from previously used scales: Bad/good, like/dislike, irritating/not irritating, boring/interesting were taken from Mitchell and Olsen (1981), unpleasant/pleasant and unfavorable/favorable were from MacKenzie and Lutz (1989) and offensive/not offensive from Droge (1989). Across the four conditions this scale showed acceptable level of internal consistency with Cronbach's alphas of $.884, .860, .835$ and .827. A $_{\text {br }}$ scale, included as it too is a mediator of purchase intention, was based on work by Gardner (1985) and comprised six items, bad/good, like/dislike, pleasant/unpleasant, high quality/poor quality, tasteful/tasteless and expensive/inexpensive with an exploratory factor analysis producing Cronbach's alphas of $.863, .869, .865$ and .869 . Items loaded as predicted on to separate factors. For both dependent variables, items were scored on a seven-point scale.

\section{Results}

To test the hypothesis, a repeated measures MANOVA was run with the results shown in tables 3 and 4 . The dependent measures were summated $A_{\text {ad }}$ and $A_{\mathrm{br}}$ constructed by summating ratings from the relevant and irrelevant advertisements. Midpoints for these scales are 49 and 42, respectively (higher score represent more positive ratings). One within-subjects factor and three between-subjects factors were included in the models. The within-subject factor, relevance, comprised of the summated scores for both treatment stimulus replications. This summation was deemed acceptable because when the scores for each replication were treated as a separate within subjects factor in the models, no unexpected interactions with the other factors were found. The between-subject factors were gender, level of nudity and type of appeal. Descriptive statistics appear in Appendix 1.

Table 3: Results of repeated measured MANOVA: Within subjects effects 
Table 4: Results of repeated measured MANOVA: Between subjects effects

H1 (a) predicted that for relevant products, women will respond positively to Intimate appeals and will prefer them to Objectified appeals. The MANOVA shows a main effect for type of appeal (Ad Type: $F_{1,120}=13.776, p<.000$, and $\left.\mathrm{A}_{\text {br Type }}: F_{1,120}=11.114, p=.001\right)$ with the descriptive statistics confirming that the Intimate appeals are preferred to Objectified appeals $\left(M_{\text {AadIntimate }}=54.58\right.$ vs. $M_{\text {AadObjectified }}=48.59$ and $M_{\text {AbrIntimate }}=44.60$ vs. $\left.M_{\text {AbrObjectified }}=39.75\right)$. Specifically, women rated the Intimate appeals higher than the Objectified appeals for both $\mathrm{A}_{\mathrm{ad}}$ and $\mathrm{A}_{\mathrm{br}}\left(M_{\text {AadIntimate }}=50.99\right.$ vs. $M_{\text {AadObjectified }}=44.64, t=2.41, d f 72, p=.019$ and $M_{\text {AbrIntimate }}=42.42$ vs. $\left.M_{\text {AbrObjectified }}=37.54, t=1.95, d f 72, p=.055\right)$. To determine whether women's responses were positive for either the Intimate or Objectified appeals, these were compared to scale midpoints. In line with the predictions, only the Intimate Relevant conditions were rated positively $\left(M_{\text {AadIntimateRelevant }}=58.20, t=5.61, d f 48, p<.001\right.$ and $\left.M_{\text {AbrIntimateRelevant }}=47.73, t=3.51, d f 48, p=.001\right)$. See Appendix 1 for other results. Therefore, Hypothesis 1 (a) is supported.

Similarly, hypothesis 1 (b) predicted that men would also prefer Intimate to Objectified appeals, but they will evaluate both Intimate and Objectifying appeals featuring relevant products, positively. The results support this. Intimate appeals were preferred to the Objectified appeals $M_{\text {AadIntimate }}=61.92$ vs. $M_{\text {AadObjectified }}=51.88, t=2.90, d f 52, p=.005$ and $M_{\text {AbrIntimate }}=49.04$ vs. $\left.M_{\text {AbrObjectified }}=41.58, t=3.20, d f 52, p=.002\right)$. In addition, both the Intimate Relevant and Objectified Relevant conditions were rated positively compared to the scale mid-point $\left(M_{\text {AadIntimateRelevant }}=67.71, t=9.11, d f 23, p<.001, M_{\text {AbrIntimateRelevant }}=55.21\right.$, $t=7.82, d f 23, \mathrm{p}<.001, M_{\text {AadObjectifiedRelevant }}=57.53, t=3.53, d f 29, p=001$ and $\left.M_{\text {AbrObjectifiedRelevant }}=46.80, t=2.51, d f 29, p=.018\right)$. 
In line with predictions made by the evolutionary psychology literature, hypothesis 1 (c) stated that irrespective of whether intimate or objectifying posing is used, men will respond more favorably to sexual appeals compared to women. This is supported by the MANOVA, which shows a main effect for gender $\left(\mathrm{A}_{\text {ad Gender: }} F_{1,120}=17.355, p<.000\right.$, and $\mathrm{A}_{\text {br Gender: }} F_{1}$, $120=8.801, p=.004)$ with the descriptive statistics showing the means scores for $A_{\mathrm{ad}}$ and $\mathrm{A}_{\mathrm{br}}$ are higher for males compared to females $\left(M_{\text {AadMale }}=56.34\right.$ vs. $M_{\text {Aadfemale }}=48.84, t=3.45, d f$ $126, p=.001$ and $M_{\text {AbrMale }}=44.90$ vs. $\left.M_{\text {AbrFemale }}=40.77, t=2.33, d f 126, p=.021\right)$. This difference is also seen between the men and women for the Intimate appeals $\left(M_{\text {AadMaleIntimate }}=\right.$ 61.92 vs. $M_{\text {AadfemaleIntimate }}=50.99, t=3.94, d f 71, p<.001$ and $M_{\text {AbrMaleIntimate }}=49.04$ vs. $\left.M_{A b r \text { FemaleIntimate }}=42.12, t=2.77, d f 71, p=.007\right)$ and the Objectified appeals in the $\mathrm{A}_{\mathrm{ad}}$ condition $\left(M_{\text {AadMaleObjectified: }}=51.88\right.$ vs. $\left.M_{\text {AadfemaleObjectified }}=46.44, t=2.21, d f 53, p<.032\right)$. It is not found in the $\mathrm{A}_{\mathrm{br}}$ Objectified condition $\left(M_{\text {AbrMaleObjectified: }}\right.$ 41.58, vs. $M_{\text {AbrFemaleObjectified: }}=$ 37.54, $t=1.58$, df 53, $p=.119)$. This specific result is discussed in detail later. Overall, hypothesis 1 (c) is supported.

Finally hypothesis 2 predicted that irrespective of the posing used both genders will prefer adverts using lower levels of nudity. In support of this, the MANOVA shows a main effect for level of nudity ( $A_{\text {ad Level: }} F_{1,120}=5.126, p=.025$, and $\left.A_{\text {br Level }}: F_{1,120}=5.198, p=.024\right)$ but does not show an interaction between gender and level of appeal $\left(A_{\text {ad Level: }} F_{1,120}=.624, p\right.$ $=.431$, and $\left.A_{\mathrm{br}}: F_{1,120}=.027, p=.870\right)$. This effect is in the expected direction with low nudity preferred to high nudity overall $\left(M_{\text {AadMild }}=54.24\right.$ vs. $M_{\text {Aad } O v e r t}=49.56, t=2.12, d f 126$, $p=.036$ and $M_{\text {AbrMild }}=44.48$ vs. $M_{\text {AbrOvert }}=40.34, t=2.36, d f 126, p=.020$. However, whereas a preference was found for men regarding $\mathrm{A}_{\mathrm{ad}}\left(M_{\mathrm{Aad} M a l e M i l d:}=59.68 \mathrm{vs} . M_{\text {AadMaleOvert }}\right.$ $=52.75, t=1.94, d f 52, p=.058)$ it was only marginally significant for $\mathrm{A}_{\mathrm{br}}\left(M_{\text {AbrMaleMild }}=\right.$ 47.09 vs. $\left.M_{\text {AbrMaleOvert }}=42.54, t=1.85, d f=52, p=.070\right)$. In addition, whilst the results for women were in the predicted direction, they were not significant $\left(M_{\text {AadfemaleMild }}=50.33 \mathrm{vs}\right.$. 
$M_{\text {AadfemaleOvert }}=47.19, t=1.23, d f 72, p=.224$ and $M_{\text {AbrFemaleMild }}=42.62$ vs. $M_{\text {AbrFemaleOvert }}=$ $38.71, t=1.63, d f 72, p=.107)$. Therefore Hypothesis 2 is only partially supported.

\section{Discussion and recommendations}

The research examined how to communicate to a mixed gender audience using sexual appeals. This remains an important question considering the range of situations where this approach is used to target products to men or women or where organisations must consider the non-target group reactions. Guidance on how to do this was based on evidence from consumers' responses to sexual appeals, studies exploring what the different sexes find attractive and body language literature.

Overall, we hypothesized that when trying to appeal to both genders, the best approach would be to create adverts focussing more on the cues and traits that women find attractive. This was operationalised using non-verbal behavioural elements to create an intimate, stable relationship between the models (a trait that also appeals to men) and contrasted with an appeal highlighting sexual objectification. As expected, because of the presence of an opposite sex model, both genders preferred the Intimate appeals.

A preference for one condition is not however the same as a positive reaction to it. To achieve this, our results suggest advertisers should use low levels of nudity with the Intimate appeals and use it only to promote sexually relevant products as this mirrors the only conditions in which both genders responded positively on both dependent variables (see Appendix 1).

This research also supports existing literature showing a gender effect when couples are used (Sciglimpaglia, Belch, and Cain 1978; Smith et al. 1995) and expands this body to show the effect when different types of appeal are used, even ones explicitly designed to appeal to women. We note that this is not seen in the $A_{\text {br }}$ Objectified condition. The lower scores by 
men here may be due to consideration of the advertiser motives and judging the use of this type of appeal as manipulative and exploitative (Campbell and Kirmani 2000).

Overall, however, we conclude that whilst men and women can be advertised to using the same type of sexual appeal, it is still likely to create a more positive response in men. The difference may be due to the visual medium being more suited to arousing male sexuality than for women (Roney 2003). This reaction may also be extenuated by women's stronger negative stimulus avoidance response (Kamhawi and Grabe 2008). Plutchik (1980) and others show that humans have a pervasive tendency to classify incoming stimulus as either good or bad (affective processing). Kamhawi and Grabe (2008) showed women, when compared to men, are more likely to avoid something they classify as bad. This avoidance manifests itself in actions such as liking it less and identifying with the characters less.

Whilst finding an overall effect for level of nudity, where lower levels are preferred, this relationship was only significant for men's $A_{\mathrm{ad}}$. That is, they preferred the mild appeals to those that were more overt. This work indicates that men do not necessarily prefer advertisements showing higher levels of female nudity (Reichert, LaTour, and Kim 2007; LaTour 1990). Indeed it appears that their negative reaction to seeing more of the male model appears to override their preference for seeing more of the female. Griskevicius et al. (2009) provide an explanation of this effect and why men react negatively to male models in sexual appeals. At higher levels of nudity, the male model is demonstrating his potentially superior physical resources. As the male respondents do not have the option of direct aggressions, then resorting to indirect forms, they react negatively to the model and the advert.

Regarding the lack of relationship found with the other dependent measures, we believe the most likely reason for this is the relatively mild form of 'overt' manipulation used being too weak to elicit the expected reaction in individual cells. In future research even higher 
levels of overtness, including implied and actually nudity should be investigated along with sexually suggestive taglines and other contextual cues as to the activities taking place.

In conclusion, this study shows that it is possible to appeal to men and women simultaneously when using sexual appeals. In addressing this, it demonstrates, in detail, the type of posing and appropriate body language to use, and hence it has significant benefits for practitioners. In so doing, it also builds a picture of how to develop sexual appeals that work better for women and that certain types of adverts can be inappropriate for men. By building the hypotheses on human sexual response and body language literature, a conceptual explanation for these findings and previous work into this type of appeal is given.

This research does not of course answer all the questions about how to advertise to both genders simultaneously, nor, due to choices taken in the construction of the adverts, were all advertising design options examined. Future work must examine the responses of people with homosexual and bisexual sexual preferences. It would also be interesting to test the use of intimacy in multimedia and non-visual media. As we concentrated only on visual stimuli, further work on exposure rates that work for both genders would be useful. Methodologically, the adverts were shown on computer screens rather than in print form and we did not explore the information processing styles of the respondents. We used culturally bound models (Caucasians with dark hair) and though overall they were rated as attractive, work is required with different types of models. The results should also be tested with different samples including older more conservative groups, as age and student status can be expected to affect the findings.

Overall this research allows us, within the limitations discussed above, to make a contribution to work explaining how to appeal to mixed gender audiences. We recommend using appeals that are based on clothed models demonstrating intimacy, relationships and 
equality rather than ones just showing sexy bodies. Critically, these should only be used for sexually relevant products. 


\section{References}

Belch, Michael A, Barbro E Holgerson, George E Belch, and Jerry Koppman. 1982. "Psychophysiological And Cognitive Responses To Sex In Advertising." Advances in Consumer Research 9 (1): 424-427.

Black, I. R., P. Morton, and G. Organ. 2010. "The Effect of Personality on Response to Sexual Appeals." European Journal of Marketing 44 (9/10): 1453 - 1477.

Blythe, Phillip W, George F Miller, and Peter M Todd. 1996. Human simulation of adaptive behavior: Interactive studies of pursuit, evasion, courtship, fighting, and play. Paper read at From animals to animats 4: Proceedings of the Fourth International Conference on Simulation of Adaptive Behavior, at Cambridge, MA.

Bower, Amanda B, and Stacy Landreth. 2001. "Is Beauty Best? Highly Versus Normally Attractive Models in Advertising." Journal of Advertising 30 (1): 1-12.

Braun, Margaret F, and Angela Bryan. 2006. "Female waist-to-hip and male waist-to-shoulder ratios as determinants of romantic partner desirability." Journal of Social and Personal Relationships 23 (5): 805-819.

Burriss, Robert P, and Anthony C Little. 2006. "Effects of partner conception risk phase on male perception of dominance in faces." Evolution and Human Behavior 27 (4): 297-305.

Buss, David M. 1989. "Sex differences in human mate preference: Evolutionary Hypotheses tested in 37 cultures." Behavioral and Brain Sciences 12 (1): 1-49.

Buss, David M, and Micheal Barnes. 1986. "Preferences in human mate selection." Journal of Personality and Social Psychology 50 (3): 559-570.

Buss, David M, and Lisa A Dedden. 1990. "Derogation of Competitors." Journal of Social and Personal Relationships 7 (3): 395-422.

Buss, David M, and Todd K Shackelford. 1997. "From vigilance to violence: Mate retention tactics in married couples." Journal of Personality and Social Psychology 72: 346-361.

Calder, Bobby J, and Alice M Tybout. 1999. "A Vision of Theory, Research, and the Future of Business Schools." Journal of the Academy of Marketing Science 27 (3): 359-366.

Campbell, Margaret C, and Amna Kirmani. 2000. "Consumers use of persuasion knowledge: The effects of accessibility and cognitive capacity on perceptions of an influence agent."

Journal of Consumer Research 27 (1): 69-83.

Crosier, Keith, Tony Hernandez, Sandra Mohabir-Collins, and B. Zafer Erdogan. 1999. "The Risk of Collateral Damage in Advertising Campaigns." Journal of Marketing Management 15 (8): 837-855.

Dahl, Darren W, Jaideep Sengupta, and Kathleen D Vohs. 2009. "Sex in Advertising: Gender Differences and the Role of Relationship Commitment." Journal of Consumer Research 36 (2): 215-231. 
Droge, Cornelia. 1989. "Shaping the route to attitude change: Central versus peripheral processing through comparative versus noncomparative advertising." Journal of Marketing Research 26 (May): 193-204.

Elliott, Richard, Abigail Jones, Andrew Benfield, and Matt Barlow. 1995. "Overt sexuality in advertising: A discourse analysis of gender responses." Journal of Consumer Policy 18 (2,3): 187.

Feick, Lawrence, and Robin Higie. 1992. "The Effects of Preference Heterogeneity and Source Characteristics on Ad Processing and Judgements about Endorsers." Journal of Advertising 21 (2): 9-24.

Fennis, Bob M., Enny Das, and Marieke L. Fransen. 2012. "Print advertising: Vivid content." Journal of Business Research 65 (6): 861-864.

Gardner, Meryl P. 1985. "Does Attitude toward the ad Affect Brand Attitude under a Brand Evaluation set." Journal of Marketing Research 22 (May): 192-98.

Giebelhausen, Michael, and Thomas P. Novak. 2012. "Web advertising: Sexual content on eBay." Journal of Business Research 65 (6): 840-842.

Grammer, Karl. 1990. "Strangers meet: Laughter and nonverbal signs of interest in oppositesex encounters." Journal of Nonverbal Behavior 14 (4): 209-236.

Grammer, Karl, Bernhard Fink, Anders P Moller, and Randy Thornhill. 2003. "Darwinian aesthetics: sexual selection and the biology of beauty." Biological Review 78 (3): 385-407.

Grammer, Karl, Kirsten. B Kruck, and Magnus S Magnusson. 1998. "The courtship dance: Patterns of nonverbal synchronization in opposite-sex encounters." Journal of Nonverbal Behavior 22 (1): 1-27.

Griskevicius, Vladas, Joshua M Tybur, Steven W Gangestad, Elaine F Perea, Jenessa R Shapiro, and Kenrick T Douglas. 2009. "Aggress to Impress: Hostility as an Evolved Context-Dependent Strategy." Journal of Personality \& Social Psychology 96 (5): 980-994.

Hill, Craig A. 2002. "Gender, Relationship Stage, and Sexual Behavior: The Importance of Partner Emotional Investment within Specific Situations,." Journal of Sex Research 39 (3): 228-240.

Hill, Sarah E 2007. "Overestimation bias in mate competition." Evolution and Human Behavior 28 (2): 118-123.

Huang, Ming-Hui. 2004. "Romantic Love and Sex: Their Relationship and Impacts on Ad Attitudes." Psychology \& Marketing 21 (1): 53-73.

Huber, Jonathan D, and Edward S Herold. 2006. "Sexually overt approaches in singles bars." Canadian Journal of Human Sexuality 15 (3-4): 133-146.

Johnson, Justin P. 2013. "Targeted advertising and advertising avoidance." The RAND Journal of Economics 44 (1): 128-144. doi: 10.1111/1756-2171.12014. 
Jones, Diane Carlson. 2001. "Social Comparison and Body Image: Attractiveness Comparisons to Models and Peers Among Adolescent Girls and Boys." Sex Roles 45 (9/10): 645-664.

Kamhawi, Rasha, and Maria Elizabeth Grabe. 2008. "Engaging the Female Audience: An Evolutionary Perspective on Gendered Responses to News Valance Frames." Journal of Broadcasting \& Electronic Media 51 (1): 33-51.

Kenrick, Douglas. T., Jill. M. Sundie, Lionnel. D. Nicastle, and Gregory. O. Stone. 2001. "Can one ever be too wealthy or too chaste? Searching for nonlinearities in mate judgment." Journal of Personality and Social Psychology 80 (3): 462-471.

Laan, Ellen, Walter Everaerd, Gerdy van Bellen, and Gerrit Hanewald. 1994. "Women's sexual and emotional responses to male- and female-produced erotica." Archives of Sexual Behavior 23 (2): 153-169.

LaTour, Michael. S. 1990. "Female nudity in print advertising: an analysis of gender differences in arousal and ad response." Psychology \& Marketing 7 (1): 65-81.

LaTour, Michael. S., and Tony. L. Henthorne. 1993. "Female Nudity: Attitudes Toward the Ad and the Brand, and Implications for Advertising Strategy." Journal of Consumer Marketing 10 (3): 25-32.

LaTour, Michael. S., and Tony. L. Henthorne. 1994. "Ethical Judgments Of Sexual Appeals In Print Advertising." Journal of Advertising 23 (3): 81-90.

Leitenberg, Harold., and Kris. Henning. 1995. "Sexual fantasy." Psychological Bulletin 117 (3): 469-496.

Li, Norman. P., J. Michael. Bailey, Douglas. T. Kenrick, and Joan. A. Linsenmeier. 2002. "The necessities and luxuries of mate preferences: Testing the trade-offs." Journal of Personality and Social Psychology 82 (6): 947-955.

Li, Norman. P., and Douglas. T. Kenrick. 2006. "Sex similarities and differences in preferences for short-term mates: What, whether, and why. ." Journal of Personality and Social Psychology 90 (3): 468-489.

MacKenzie, Scott. B., and Richard. J. Lutz. 1989. "Am Empirical Examination of the Structural Antecedents of Attitude Toward the Ad in an Advertising Pretesting Context." Journal of Marketing 53 (2): 48-65.

Maisey, Douglas. S., Ellen. L. E. Vale, Piers. L. Cornelissen, and Martin. J. Tovee. 1999. "Characteristics of male attractiveness for women." Lancet 353 (9163): 1500.

Martin, Mary C. , and James. W. Gentry. 1997. "Stuck in the Model Trap: The Effects of Beautiful Models in Ads on Female Pre-Adolescents and Adolescents." Journal of Advertising 26 (2): 19-33.

Mills, Jennifer. S., Janet. Polivy, C. Peter. Herman, and Marika. Tiggemann. 2002. " Effects of exposure to thin media images: Evidence of self-enhancement among restrained eaters." Personality \& Social Psychology Bulletin 28 (12): 1687-1699. 
Mitchell, Andrew. A., and Jerry. C. Olsen. 1981. "Are Product Attribute Beliefs the Only Mediator of Advertising Effects on Brand Attitude?" Journal of Marketing Research 18 (August): 318-332.

Moore, Monica M. 1985. "Nonverbal courtship patterns in women : Context and consequences." Ethology and Sociobiology 6 (4): 237-247.

Morry, Marian. M. , and Sandra. L. Staska. 2001. "Magazine exposure: Internalization, selfobjectification, eating attitudes, and body satisfaction in male and female university students." Canadian Journal of Behavioural Science 33 (4): 269-279.

Mosher, Donald L, and Paula Maclan. 1994. "College men and women respond to X-rated videos intended for male or female audiences: Gender and sexual scripts." Journal of Sex Research 31 (2): 99-113.

Orth, Ulrich R, and Denisa Holancova. 2004. "Men's and women's responses to sex role portrayals in advertisements." International Journal of Research in Marketing 21 (1): 77-88.

Pawlowski, Boguslaw, R I Dunbar, and A Lipowicz. 2000. "Tall men have more reproductive success." Nature 403 (6766): 156.

Perper, Timothy, and David L Weis. 1987. "Proceptive and Rejective Strategies of U.S. and Canadian College Women." The Journal of Sex Research 23 (4): 455-480.

Peterson, Richard A., and Roger A Kerin. 1977. "The Female Role in Advertisements: Some Experimental Evidence." Journal of Marketing 41 (4): 59-63.

Peterson, Robert A., and Ivan Ross. 1972. "How to Name New Brands." Journal of Advertising Research 12 (6): 29-34.

Plutchik, Robert. 1980. "A general psychoevolutionary theory of emotion." In Emotion:

Theory, research, and experience: Vol. 1. Theories of emotion, edited by Richard Plutchik and Henry Kellerman, 3-33. New York: Academic Press.

Pope, Nigel K Ll, Kevin E Voges, and Mark R Brown. 2004. "The Effect of Provocation in the Form of Mild Erotica on Attitude to the Ad and Corporate Image." Journal of Advertising 33 (1): 69-82.

Putrevu, Sanjay. 2004. "Communicating with the Sexes: Male and Female Responses to Print Advertisements." Journal of Advertising 33 (3): 51-62.

Putrevu, Sanjay. 2008. "Consumer Responses toward Sexual and Nonsexual Appeals: The Influence of Involvement, Need for Cognition, and Gender." Journal of Advertising 37 (2): 61-73.

Reichert, Tom, and Courtney Carpenter. 2004. "An Update on Sex in Magazine Advertising: 1983 to 2003." Journalism \& Mass Communication Quarterly 81 (4): 823-837. doi: $10.1177 / 107769900408100407$.

Reichert, Tom, Michael S LaTour, and John B Ford. 2011. "The Naked Truth: Revealing the Affinity for graphic Sexual Appeals in Advertising." Journal of Advertising Research 51 (2): 435-448. 
Reichert, Tom R, Michael S LaTour, and Joo. Young Kim. 2007. "Assessing the Influence of Gender and Sexual Self-Schema on Affective Responses to Sexual Content in Advertising." Journal of Current Issues and Research in Advertising 29 (2): 57-71.

Reichert, Tom R, Michael S LaTour, Jacqueline I Lambiase, and Mark Adkins. 2007. "A Test of Media Literacy Effects and Sexual Objectification in Advertising." Journal of Current Issues \& Research in Advertising 29 (1): 81-92.

Renninger, Lee Ann, T. Joel Wade, and Karl Grammer. 2004. "Getting that female glance: Patterns and consequences of male nonverbal behavior in courtship contexts." Evolution and Human Behavior 25 (6): 416-431.

Roney, James R 2003. "Effects of visual exposure to the opposite sex: Cognitive aspects of mate attraction in human males." Personality and Social Psychology Bulletin 29 (3): 393-404.

Rossiter, John R. 2012. "Editorial: JBR Special issue on executional elements in advertising." Journal of Business Research 65 (6): 829-830.

Rupp, HeatherA, and Kim Wallen. 2008. "Sex Differences in Response to Visual Sexual Stimuli: A Review." Archives of Sexual Behavior 37 (2): 206-218. doi: 10.1007/s10508-0079217-9.

Sciglimpaglia, Donald, Michael A Belch, and Richard F Cain. 1978. Demographic And Cognitive Factors Influencing Viewers' Evaluations Of 'Sexy' Advertisements. Paper read at Advances in Consumer Research, at Miami.

Sengupta, Jaideep, and Darren W Dahl. 2008. "Gender-Related Reactions to Gratuitous Sex Appeals in Advertising." Journal of Consumer Psychology 18 (1): 62-78

Simpson, Penny M, Steve Horton, and Gene Brown. 1996. "Male Nudity in Advertisements: A Modified Replication and Extension of Gender and Product Effects." Journal of the Academy of Marketing Science 24 (3): 257.

Smith, Stephen M, Curtis P Haugtvedt, John M Jadrich, and Mark R Anton. 1995. "Understanding Responses to Sex Appeals in Advertising: An Individual Difference Approach." Advances in Consumer Research 22 (1): 735-739.

Stankiewicz, Julie M, and Francine Rosselli. 2008. "Women as Sex Objects and Victims in Print Advertisements." Sex Roles 58 (7-8): 579-589. doi: 10.1007/s11199-007-9359-1.

Striegel-Moore, Ruth, Gail McAvay, and Judith Rodin. 1986. "Psychological and behavioral correlates of feeling fat in women." International Journal of Eating Disorders 5 (5): 935-947.

Symons, Donald. 1979. The evolution of human sexuality. New York: Oxford University Press.

Weeden, Jason, and John Sabini. 2005. "Physical Attractiveness and Health in Western Societies: A Review." Psychological Bulletin 131 (5): 635-653.

Youn, Gahyun. 2006. "Subjective Sexual Arousal in Response to Erotica: Effects of Gender, Guided Fantasy, Erotic Stimulus, and Duration of Exposure." Archives of Sexual Behavior 35 (1): 87-97. 
Appendix 1. Descriptive statistics for $A_{b r}$ and $A_{B r}$ including $P$ values vs. scale midpoints (49 for $A_{b r}, 42$ for $A_{b r}$ )

\begin{tabular}{|c|c|c|c|c|c|c|c|c|c|c|c|c|c|c|c|c|c|c|c|c|}
\hline \multirow[b]{2}{*}{ Type } & \multirow{2}{*}{\multicolumn{2}{|c|}{$\begin{array}{l}\text { Level of } \\
\text { nudity }\end{array}$}} & \multicolumn{3}{|c|}{$\begin{array}{l}\text { Summated Aad for relevant } \\
\text { products }\end{array}$} & \multicolumn{3}{|c|}{$\begin{array}{l}\text { Summated } A_{\text {br }} \text { for irrelevant } \\
\text { products }\end{array}$} & \multicolumn{3}{|c|}{$\overline{\text { Summated } A_{\mathrm{br}}}$} & \multicolumn{3}{|c|}{$\begin{array}{l}\text { Summated } \mathrm{A}_{\mathrm{br}} \text { for relevant } \\
\text { products }\end{array}$} & \multicolumn{3}{|c|}{$\begin{array}{l}\text { Summated } \mathrm{A}_{\mathrm{br}} \text { for irrelevant } \\
\text { products }\end{array}$} & \multicolumn{3}{|c|}{ Summated $\mathrm{A}_{\mathrm{br}}$} \\
\hline & & & Male & Female & Total & Male & Female & Total & Male & Female & Total & Male & Female & Total & Male & Female & Total & Male & Female & Total \\
\hline \multirow[t]{12}{*}{ Intimate } & \multirow[t]{4}{*}{ Low } & $M$ & 69.23 & 59.21 & 62.39 & 60.15 & 43.61 & 48.85 & $\begin{array}{l}64.69 \\
\end{array}$ & 51.41 & $55 . .62$ & 57.77 & 49.54 & 52.15 & 44.46 & 37.61 & 39.78 & 51.12 & 43.57 & 45.96 \\
\hline & & SD & 12.75 & 12.00 & 12.97 & 17.30 & 15.81 & 17.86 & 14.06 & 11.73 & 13.83 & 8.45 & 13.30 & 12.49 & 11.25 & 13.80 & 13.31 & 6.72 & 12.22 & 11.27 \\
\hline & & $P$ & $.000^{* *}$ & $.000^{* *}$ & $.000 * *$ & $.038^{*}$ & .082 & .958 & $.002 *$ & .287 & $.004 *$ & $.000 * *$ & $.006^{*}$ & $.000 * *$ & .446 & .104 & .292 & $.000^{* *}$ & .502 & $.030 *$ \\
\hline & & $\mathrm{N}$ & 13 & 28 & 41 & 13 & 28 & 41 & 13 & 28 & 41 & 13 & 28 & 41 & 13 & 28 & 41 & 13 & 28 & 41 \\
\hline & \multirow[t]{4}{*}{ High } & $M$ & 65.91 & 56.86 & 59.97 & 51.36 & 44.00 & 46.53 & 58.64 & 50.43 & 53.25 & 52.18 & 45.33 & 47.69 & 41.00 & 36.43 & 38.00 & 46.59 & 40.88 & 42.84 \\
\hline & & SD & 5.58 & 10.91 & 10.29 & 15.32 & 8.51 & 11.62 & 9.85 & 8.62 & 9.75 & 7.29 & 7.98 & 8.32 & 10.87 & 9.78 & 10.23 & 7.29 & 7.78 & 7.99 \\
\hline & & $P$ & $.000 * *$ & $.004 *$ & $.000^{* *}$ & .620 & $.014^{*}$ & .239 & $.009 *$ & .457 & $.019 *$ & $.001 *$ & .070 & $.001 *$ & .767 & $.017^{*}$ & $.035^{*}$ & .063 & .517 & .555 \\
\hline & & $\mathrm{N}$ & 11 & 21 & 32 & 11 & 21 & 32 & 11 & 21 & 32 & 11 & 21 & 32 & 11 & 21 & 32 & 11 & 21 & 32 \\
\hline & \multirow[t]{4}{*}{ Total } & $M$ & 67.71 & 58.20 & 61.33 & 56.13 & 43.78 & 47.84 & 61.92 & 50.99 & 54.58 & 55.21 & 47.73 & 50.19 & 42.88 & 37.10 & 39.00 & 49.04 & 42.42 & 44.60 \\
\hline & & SD & 10.06 & 11.49 & 11.85 & 16.68 & 13.07 & 15.39 & 12.44 & 10.43 & 12.19 & 8.27 & 11.42 & 11.02 & 10.98 & 12.14 & 12.01 & 7.21 & 10.54 & 10.02 \\
\hline & & $P$ & $.000^{* *}$ & $.000^{* *}$ & $.000^{* *}$ & $.048^{*}$ & $.007 *$ & .520 & $.000 * *$ & .188 & $.000^{* * *}$ & $.000^{* *}$ & $.001 *$ & $.000 * *$ & .700 & $.007 *$ & $.036^{*}$ & $.000 * *$ & .782 & $.030 *$ \\
\hline & & $\mathrm{N}$ & 24 & 49 & 73 & 24 & 49 & 73 & 24 & 49 & 73 & 24 & 39 & 73 & 24 & 39 & 73 & 24 & 39 & 73 \\
\hline \multirow[t]{12}{*}{ Objectified } & \multirow[t]{4}{*}{ Low } & $M$ & 58.93 & 52.36 & 56.15 & 51.73 & 42.82 & 47.96 & 55.33 & 47.59 & 52.06 & 47.33 & 43.64 & 45.77 & 39.87 & 36.73 & 38.54 & 43.60 & 40.18 & 42.15 \\
\hline & & SD & 12.96 & 10.22 & 12.12 & 12.74 & 15.62 & 14.44 & 10.48 & 11.91 & 11.55 & 10.27 & 9.60 & 9.97 & 9.01 & 14.11 & 11.30 & 8.81 & 11.48 & 9.96 \\
\hline & & $P$ & $.010^{*}$ & .309 & $.006^{*}$ & .420 & .219 & .717 & $.035^{*}$ & .703 & .189 & .064 & .584 & .065 & .374 & .244 & .131 & .383 & .611 & .844 \\
\hline & & $\mathrm{N}$ & 15 & 11 & 26 & 15 & 11 & 26 & 15 & 11 & 26 & 15 & 11 & 26 & 15 & 11 & 26 & 15 & 11 & 26 \\
\hline & \multirow[t]{4}{*}{ High } & $M$ & 56.13 & 49.00 & 52.69 & 40.73 & 35.64 & 38.28 & 48.43 & 42.32 & 45.38 & 46.27 & 39.93 & 43.21 & 32.87 & 31.00 & 31.97 & 39.57 & 35.46 & 37.59 \\
\hline & & $\mathrm{SD}$ & 13.82 & 10.98 & 12.83 & 16.85 & 11.63 & 14.54 & 14.20 & 10.62 & 12.76 & 11.01 & 7.82 & 9.97 & 12.60 & 8.01 & 10.49 & 9.90 & 7.17 & 8.79 \\
\hline & & $P$ & .065 & 1.0 & .133 & .078 & $.001 *$ & $.000^{* *}$ & .879 & $.035^{*}$ & .149 & .156 & .340 & .520 & $.014^{*}$ & $.000^{* *}$ & $.000^{* *}$ & .506 & $.010^{*}$ & $.035^{*}$ \\
\hline & & $\mathrm{N}$ & 15 & 14 & 29 & 15 & 14 & 29 & 15 & 14 & 29 & 15 & 14 & 29 & 15 & 14 & 29 & 15 & 14 & 29 \\
\hline & \multirow[t]{4}{*}{ Total } & $M$ & 57.53 & 50.48 & 54.33 & 46.23 & 38.80 & 42.85 & 51.88 & 44.64 & 48.59 & 46.80 & 41.56 & 44.42 & 36.37 & 33.52 & 35.07 & 41.58 & 37.54 & 39.75 \\
\hline & & SD & 13.24 & 10.57 & 12.50 & 15.71 & 13.72 & 15.17 & 12.76 & 11.28 & 12.54 & 10.48 & 8.67 & 9.96 & 11.34 & 11.23 & 11.28 & 9.43 & 9.41 & 9.55 \\
\hline & & $P$ & $.001^{*}$ & .491 & $.003 *$ & .343 & $.001 *$ & $.004 *$ & .226 & .065 & .810 & $.018^{*}$ & .802 & .077 & $.011^{*}$ & $.001 *$ & $.000 * *$ & .929 & $.047 *$ & .193 \\
\hline & & $\mathrm{N}$ & 30 & 25 & 55 & 30 & 25 & 55 & 30 & 25 & 55 & 30 & 25 & 55 & 30 & 25 & 55 & 30 & 25 & 55 \\
\hline
\end{tabular}




\begin{tabular}{|c|c|c|c|c|c|c|c|c|c|c|c|c|c|c|c|c|c|c|c|c|}
\hline \multirow[t]{12}{*}{ Total } & \multirow[t]{4}{*}{ Low } & $M$ & 63.71 & 57.28 & 59.97 & 55.64 & 43.38 & 48.51 & 59.68 & 50.33 & 54.24 & 52.18 & 47.87 & 49.67 & 42.00 & 37.36 & 39.30 & 47.09 & 42.62 & 44.49 \\
\hline & & SD & 13.66 & 11.81 & 12.92 & 15.34 & 15.55 & 16.51 & 12.94 & 11.76 & 13.02 & 10.70 & 12.54 & 11.91 & 10.19 & 13.71 & 12.49 & 8.65 & 11.97 & 10.86 \\
\hline & & $P$ & $.000^{* *}$ & $.000^{* *}$ & $.000 * *$ & $.030^{*}$ & $.030 *$ & .808 & $.000 * *$ & .483 & $.002 *$ & $.000 * *$ & $.006^{*}$ & $.000^{* *}$ & 1.00 & $.041^{*}$ & .081 & $.002 *$ & .750 & .056 \\
\hline & & $\mathrm{N}$ & 28 & 39 & 67 & 28 & 39 & 67 & 28 & 39 & 67 & 28 & 39 & 67 & 28 & 39 & 67 & 28 & 39 & 67 \\
\hline & \multirow[t]{4}{*}{ High } & $M$ & 60.27 & 53.71 & 56.51 & 45.23 & 40.66 & 42.61 & 52.75 & 47.19 & 49.56 & 48.77 & 43.17 & 45.56 & 36.31 & 34.26 & 35.13 & 42.54 & 38.71 & 40.34 \\
\hline & & SD & 11.99 & 11.46 & 12.04 & 16.78 & 10.57 & 13.63 & 13.35 & 10.16 & 11.85 & 9.90 & 8.25 & 9.34 & 12.37 & 9.39 & 10.71 & 9.42 & 7.91 & 8.72 \\
\hline & & $P$ & $.000^{* *}$ & $.020^{*}$ & $.000 * *$ & .263 & $.000^{* * *}$ & $.001 *$ & .164 & .298 & .715 & $.002 *$ & .407 & $.004 *$ & $.027^{*}$ & $.000 * *$ & $.000^{* *}$ & .596 & $.035^{*}$ & .286 \\
\hline & & $\mathrm{N}$ & 26 & 35 & 61 & 26 & 35 & 61 & 26 & 35 & 61 & 26 & 35 & 61 & 26 & 35 & 61 & 26 & 35 & 61 \\
\hline & \multirow[t]{4}{*}{ Total } & $M$ & 62.06 & 55.59 & 58.32 & 50.63 & 42.09 & 45.70 & 56.34 & 48.84 & 52.01 & 50.54 & 45.65 & 47.71 & 39.26 & 35.89 & 37.31 & 44.90 & 40.77 & 42.51 \\
\hline & & SD & 12.88 & 11.71 & 12.58 & 16.74 & 13.41 & 15.43 & 13.47 & 11.07 & 12.65 & 10.37 & 10.91 & 10.92 & 11.55 & 11.89 & 11.82 & 9.23 & 10.37 & 10.08 \\
\hline & & $P$ & $.000^{* * *}$ & $.000^{* * *}$ & $.000 * *$ & .478 & $.000^{* *}$ & $.017^{*}$ & $.000^{* * *}$ & .861 & $.003^{*}$ & $.000 * *$ & $.005^{*}$ & $.000 * *$ & .087 & $.000 * *$ & $.000^{* *}$ & $.011^{*}$ & .399 & .378 \\
\hline & & $\mathrm{N}$ & 54 & 74 & 128 & 54 & 74 & 128 & 54 & 74 & 128 & 54 & 74 & 128 & 54 & 74 & 128 & 54 & 74 & 128 \\
\hline
\end{tabular}

